التحليل الطيفي لنماذج الترب في مواقع التلوث البيئي في محافظة نينوى باستخدام تقنيات التحس النائي

\author{
فائزة حميدي جاسم \\ قسم علوم الأرض جائرة \\ كلية العلوم/ جامعة الموصل
}

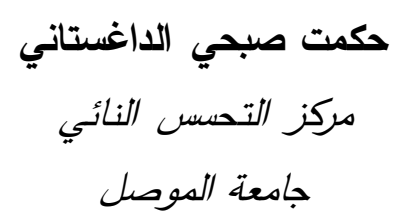

(تاريخ الاستلام 2019/10/19 تاريخ القبول 2020/5/2)

\begin{abstract}
الملخص
تثير نتائج تطيل وتفسير المرئيات الفضائية المتعاقبة زمنيا للفترة مابين (1987-2007) في محافظة

نينوى إلى وجود شذوذ طيفي مطي في بعض المناطق مما يعكس تغيرا واضحا في نمط الانعكاسية الطيفية فيها.

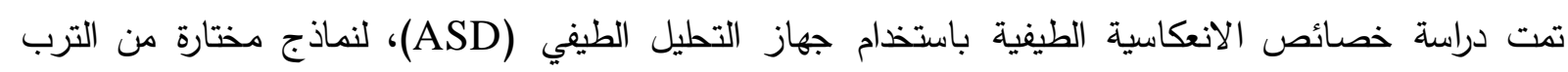

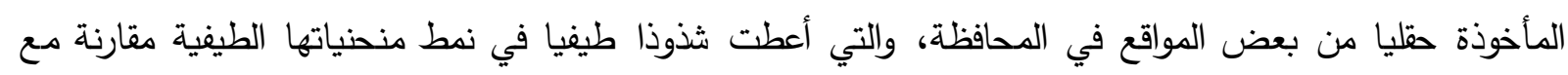

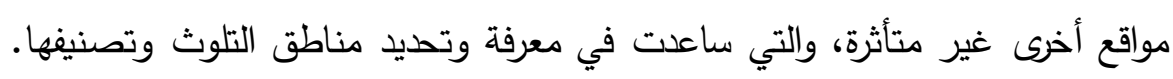

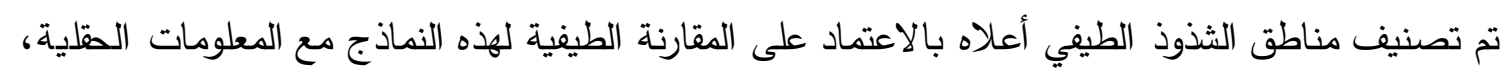

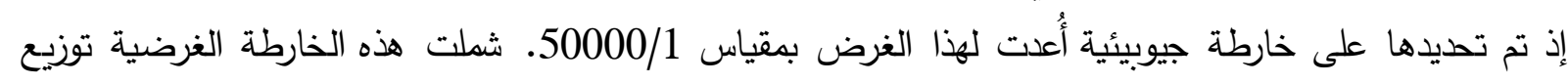

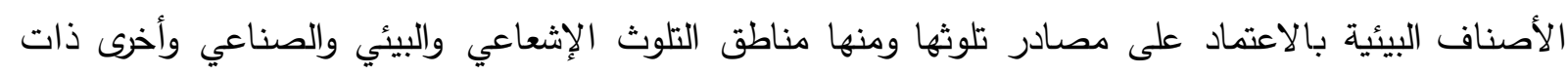
نشاط عسكري. الكلمات الدالة: مرئيات فضائية، محافظة نينوى، الانعكاسية الطيفية، خارطة جيوبيئة، تلوث.
\end{abstract}

\title{
Spectral analysis of soil samples in environmental pollution sites in Nineveh province, using remote sensing techniques
}

\author{
Hekmat S. AL-Daghastani \\ Remote Sensing Center \\ Mosul University
}

Fa'aza H. Jasim

Department of Geology

College of Science/ Mosul University

\begin{abstract}
The results of the analysis and interpretation of multi-date satellite images for the period between (1987-2007) in the Nineveh's province to the presence of local spectral anomalies in some areas, reflect a clear change in the pattern of spectral using reflectivity. Analyses of spectral reflectivity using Analytical Spectral Devise (ASD) field Spectro Radiometer for selected samples of soils that have been taken by field work
\end{abstract}


from some sites in the province. They gave spectral anomaly in their profile patterns, compared with other unaffected sites, which have been useful in determining and locating the pollution sites and its classification.

Classification of the above pollution sites has been accomplished depending on the comparison of spectral signature of these samples with the field informations. These classes are shown on Geoenvironmental thematic map prepared at scale of 1:50000. This map includes areas of radioactive contamination and environmental, indusial and other of military activity.

Keywords: satellite images, Nineveh's province, spectral reflectivity, Geoenvironmental thematic map, contamination.

\section{المقدمة}

تسلط تقنيات التحس النائي الحديثة الضوء على كثير من القضايا البيئية التي تؤثر بصورة مباشرة في حياة

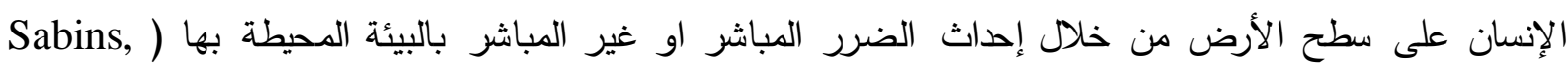
1999). تساهم هذه التقنيات الحديثة في استغلاد الوقت وتوفير الجهد في إيجاد حدود ومواقع المشكلة وإدراج الحلول المناسبة لها بما يتتاسب مع التأثيرات الناجمة عنها، ومن هذه التقنيات المتوفرة في مركز التحس النائي بجامعة الموصل جهاز التطيل الطيفي، (ASD) والذي يعمل على تحليل البصمة الطيفية لنماذج الترب والنبات والصخور حقليا ومختبريا. تساهم نتائج التحليلات هذه في مقارنة المنحنيات الناتجة للترب الملوثة مع اخرى سليمة تعطي منحنيً مثالياً لنوعها، ومن ثم دراسة سبب تغير شكل المنحنى وانعكاساته على المرئيات الفضائية الملتقطة بفترات زمنية متباينة.

اظهرت سلسلة المرئيات الفضائية الملتقطة بواسطة القدر الاصطناعي لاندسات جدول رقم (1) شذوذا طيفيا في مناطق واقعة ضمن محافظة نينوى، وعند مقارنتها مع مرئيات اخرى لسنين سابقة لوحظ انعدام هذا الثذوذ

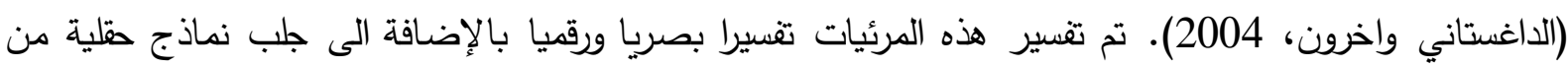
هذه المواقع لتحديد نوع وسبب هذا الثذوذ الطيفي.

تهدف الدراسة الحالية الى استخدام الوسائل الحديثة والمتطورة لتتنيات التحس النائي كهجاز التحليل الطيفي والبرامجيات الحديثة المرافقة لها في الكثف عن مناطق التلوث البيئي في محافظة نينوى وتثبيتها على خارطة جيوبيئية غرضية حديثة، الى جانب تقديم المعالجات والطول المناسبة للحد من مخاطر هذا التلوث.

\section{الموقع الجغرافي لمنطقة الاراسة}

تقع منطقة الدراسة في محافظة نينوى (شمال غربي العراق) والتي تتألف من عدة مواقع متأثرة بظاهرة الثذوذ

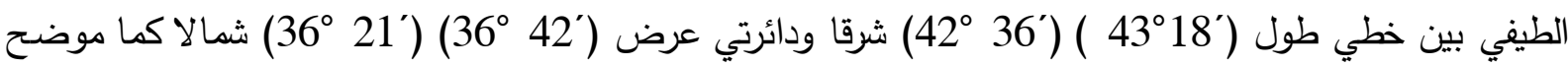
في جزء من المرئية المستقعة من البيان الفضائي الملتقط من القدر الاصطناعي لاندسات (الشكل 1). 
التحليل الطيفي لنماذج الترب في مواقع التلوث البيئي في محافظة نيذوى باستخدام تقنيات التحس النائي

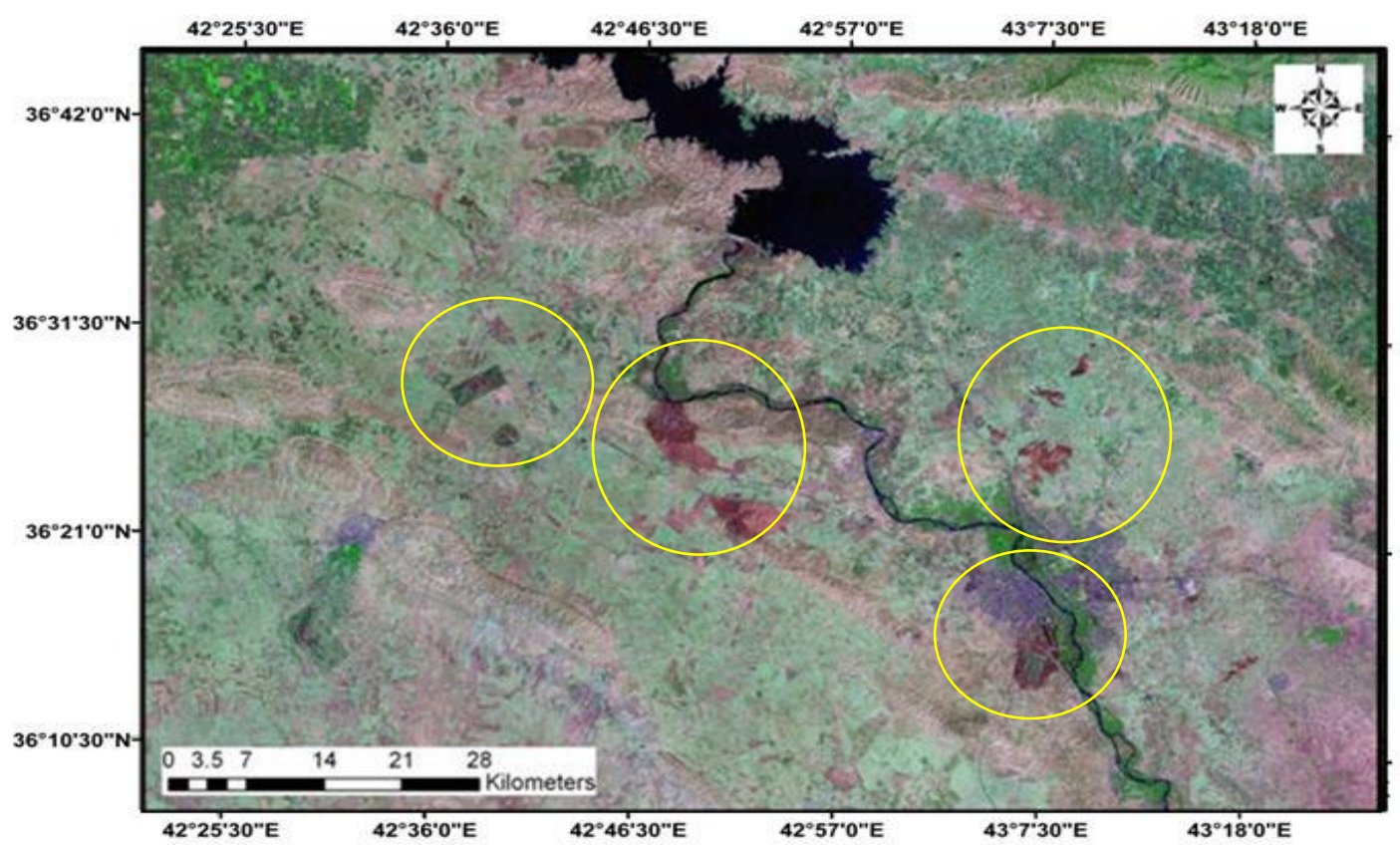

الشكل 1: يوضح منطقة الدراسة ومناطق الثذوذ الطيفي فيها والمتمثلة باللون القهوائي لمرئية ملتقطة عام 2001.

$$
\text { أسلوب العمل }
$$

قتصاص منطقة الدراسة من المرئيات الفضائية التي تحتوي الثذوذ الطيفي وذلك باستخدام برنامج ايرداس

$$
\text { ERDAS v. } 9.1
$$

تفسير المرئيات بصريا باستخدام عناصر تفسير معطيات التحس النائي الأساسية، حيث تستخدم هذه

العناصر في معرفة وتحديد الظواهر الأرضية وتساعد المفسر على فصل وتصنيف الوحدات الجيوبيئية عن

$$
\text { بعضها البعض. }
$$

تطيل نماذج الترب الحقلية طيفيا باستخدام جهاز التحليل الطيفي (ASD) وعرض النتائج بشكل منحنيات

\begin{tabular}{|c|c|c|c|}
\hline المتحس & الصف/(المسار & المزم الطيفية & تاريخ \\
\hline TM & $170 / 35$ & $7,4,2$ & 1987 \\
\hline TM & $170 / 35$ & $5,4,3$ & 1988 \\
\hline TM & $170 / 35$ & $7,4,1$ & 2001 \\
\hline TM & $170 / 35$ & $5,4,3$ & 2004 \\
\hline ETM & $170 / 35$ & $3,2,1$ & 2007 \\
\hline
\end{tabular}

الجدول 1: يوضح تفاصيل المرئيات المستخدمة في الدراسة. 


\section{أسلوب تفسير وتحليل معطيات التحسس النائي}

أولاً: التفسير البصري

يعد التفير البصري احد اهم أصول استخدام تقنيات التحس النائي و الأساس في عملية التفسير اليدوي للصور الجوية والمرئيات الفضائية، ويعتد على مبدأ تطيل وتفسير أشكال سطح الأرض باستخدام عناصر التفسير

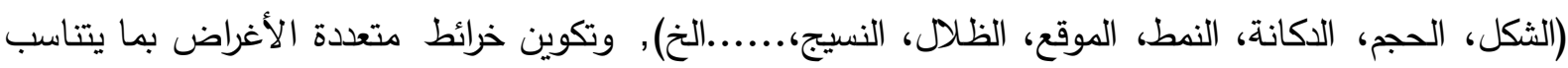
مع حاجة المستقيد (Lillesand and Kiefer, 2004). يتم الفصل بين الوحدات الجيومورفولوجية بواسطة رموز معتمدة عالميا ومتوفرة في نظام المسح الجيومورفولوجي الخاص بالمعهد الدولي لمسوحات الفضاء وعلوم الارض (ITC). وهي رموز تسهل فهم الخارطة وتحويل المرئية من مرئية فضائية ذات صفة معينة غير مفسرة إلى خارطة غرضية مفسرة تحمل رموزا وأشكالا

وحدود وحدات ارضية مصنفة حسب المنشأ التكويني لها (Verstappen and Van Zuidam, 1975). تشكل المظاهر الأرضية لعناصر أشكال سطح الأرض والتي تظهر على معطيات التحس النائي عاملا أساسيا في استخدام المنهج المورفولوجي في وصف أشكال سطح الأرض وتحليلها وتصنيفها تمهيدا لتمثيلها على التى خرائط غرضية. هذه الخرائط هي عبارة عن تمثيل لمظاهر أشكال سطح الأرض من خلال توضيحها لعدة عناصر كالثكل الخاص بهذا السطح (المورفومتري) وطبيعة مكونات المواد فيه (البنية الجيولوجية) وتأثير العامل الجيومورفولوجي السائد في المنطقة والتربة والحياة النباتية (الفلور) فضلا عن معرفة نشأتها وتطورها الجيوموفولوجي (الداغستاني، 2004).

يوضح الثكل (2) التفسير البصري للمرئية من خلا إبراز المعالم المكونة لسطح الأرض في المنطقة واستخامات الأراضي فيها، إذ يمكن ملاحظة بحيرة سد الموصل والمناطق الجبلية المنتشرة، وكنلك مركز مدينة الموصل. إما المناطق الملوثة فأنها ذات شكل وانعكاسية مميزة على سبيل المثال موقع مخازن العتاد الواقعة ضمن تركيب علان، وموقع الريحانية (أحد مواقع تخصيب اليورانيوم التابع للتصنيع العسكري) في تركيب عطشان والمناطق العسكرية كمشروع 1101 ومطاري الموصل وتلعفر غربي محافظة نينوى، الى جانب مناطق اخرى لها نفس الثذوذ الطيفي ولكن لا تعكس مناطق ذات استخدامات عسكرية كما هي مصنفة في الخارطة البيئية النهائية (الشكل 8).

ثانيا": التحليل الرقمي تم استخدام برنامج ايرداس (ERDAS) في اجراء عمليات المعالجة الرقمية على المرئيات المستقطعة التي تحوي منطقة الدراسة، وهو يعد احد اهم البرامج الرائدة والمستخدمة عالميا في مجال تفسير وتحليل معطيات التحسس النائي. يدمج برنامج ERDAS Imagine v. 9.1 بين معالجة المرئيات الفضائية ونظم المعلومات الجغرافية، وتتضمن وظائف هذا النظام استيراد وتصدير ومعاينة وتعديل وتحليل البيانات الظوية او المساحية (Raster data) والبيانات الموجهة (Vector data). إن المرئيات الفضائية هي تمثيل رقمي لعناصر سطح الأرض، اذ تخزن بيانات المرئية على شكل وحدات

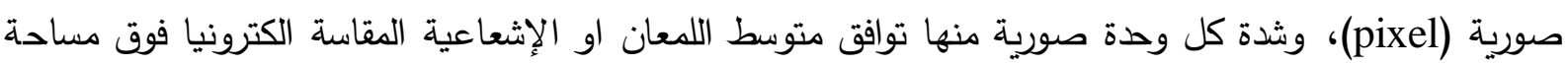
الأرض الممثلة لكل وحدة صورية. وتتألف هذه البيانات من أرقام (DN) تحمل معدل كثافة الانعكاسية المقاسة لكل وحدة صورية حقليا"، وعند عرضها على شاشة الحاسوب تظهر كمرئية. ان كل رقم في ملف المرئية هو قيمة 
ملف البيانات، فعند تطبيق عمليات المعالجة والتحسين على المرئية يتم التعامل مع القيم الرقمية لعنصر الصورة

.(Sabins, 1987)

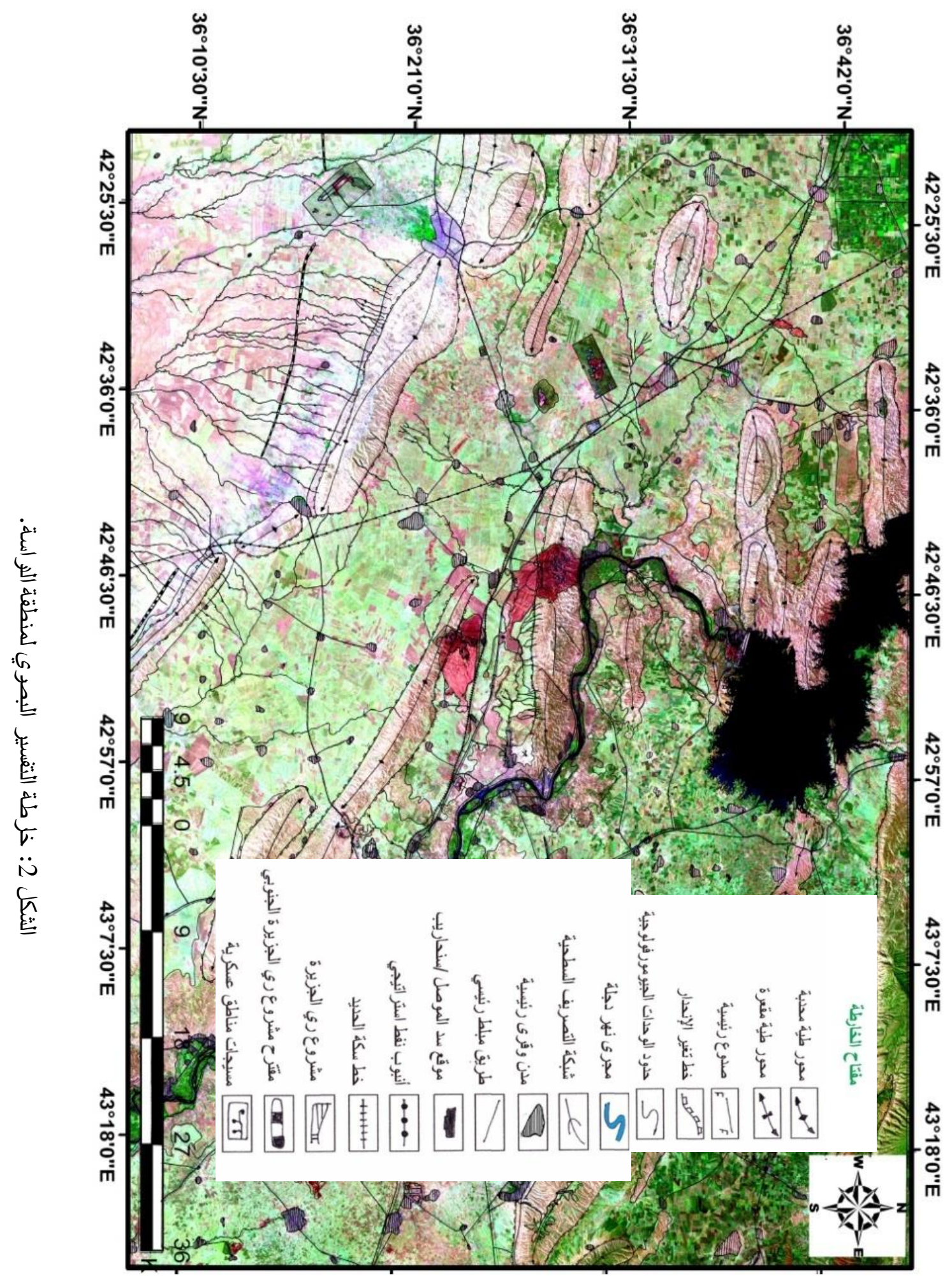




\section{تطبيق البرنامج على المرئية:}

1- إحضار وعرض المرئية: يوجد في واجهة البرنامج (الثكل 3) نافذة عرض (Viewer)، تتيح هذه النافذة للمستخدم عرض المرئية المخزونة بامتداد img، اذ تحوي هذه النافذة على العديد من القوائم والأوامر التي تستخم لعملية فتح وحفظ وإجراء عمليات التحسين والتصنيف العديدة على المرئية. 2- (قتصاص منطقة اللراسة: لكي يكون من السهل استخدام عمليات المعالجة والتحسين على المريئة يفضل اقتصاص منطقة الدراسة من المرئية الأصلية، إذ يوضح الثكل (3) عملية عرض واقتصاص وتحسين منطقة

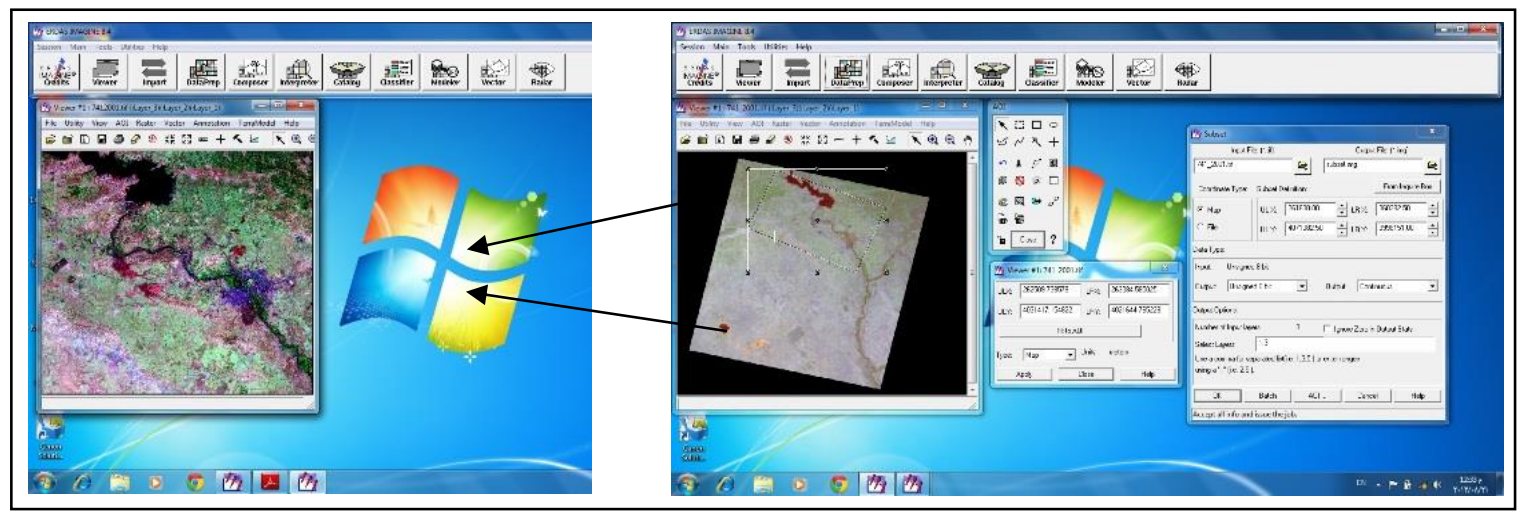

الثكل 3: يوضح عملية احضار واقتصاص منطقة اللواسة

\section{3- تحسين وتصنيف منطقة الراسة}

ان مفهوم تحسين المرئية هي عملية جعل المرئية اكثر قابلية للتقسير من اجل تطبيق محدد, وهناك عدة طرائق يمكن استخدامها في عملية التحسين (Faust, 1989). وان الهدف الاساسي من عمليات التحسين هو ابراز حة التباين بين الظواهر الأرضية وذلك ليسهل تمييزها وبالتالي تفسيرها بصريا ورقميا، ويمكن تطبيق عمليات التحسين على المرئية كاملة او على جزء منها. وهنا قمنا باقتطاع الجزء الذي يضم منطقة الدراسة من المرئية الاصلية وتطبيق عمليات التحسين عليها، ومن هذه الطرائق: طريقة إنتاج المرئية الملونة: تعد هذه الطريقة من الطرائق السريعة لتسهيل عملية التمييز بين الظواهر الأرضية وإنتاج مرئية ملونة، وذلك لان الإنسان قادر على تمييز عدد محدد من تدرجات الرمادي (Curran, 1985). يمكن

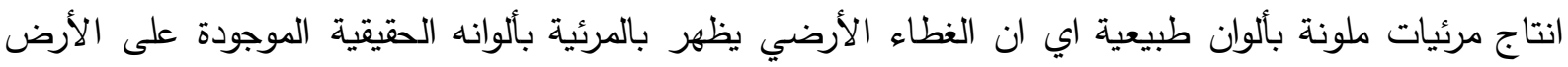
False شكل Datural color composite

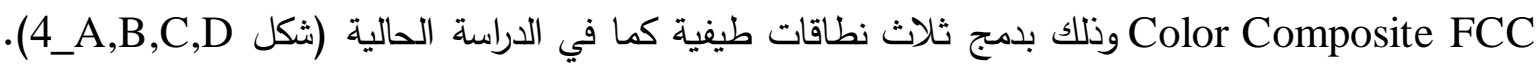
أن الفائدة الكامنة من استخدام هذه الطريقة هي التوصل الى أن ظاهرة الثذوذ الطيفي غير موجودة في المرئيات (1987-1988) (الشكل A,B/4) مقارنة بالمرئيات (2004-2007)، والتي أظهرت الثذوذ بشكل واضح كما في الشكل (C,D/4). 


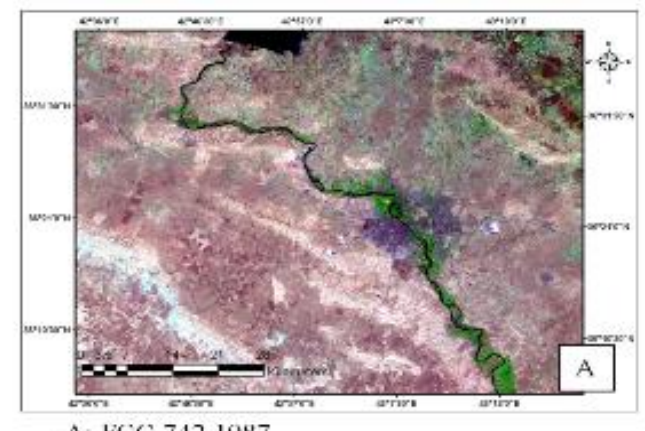

A. $\mathrm{FCC} 7421987$

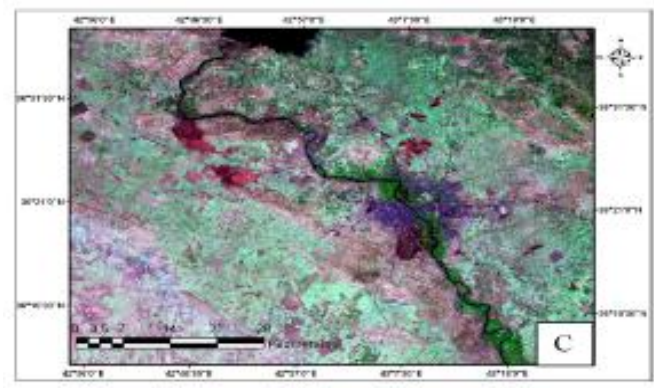

C: FCC 5432004

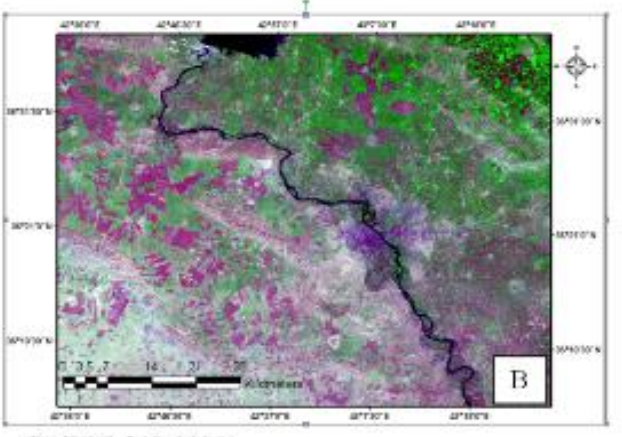

B: FCC 5431988

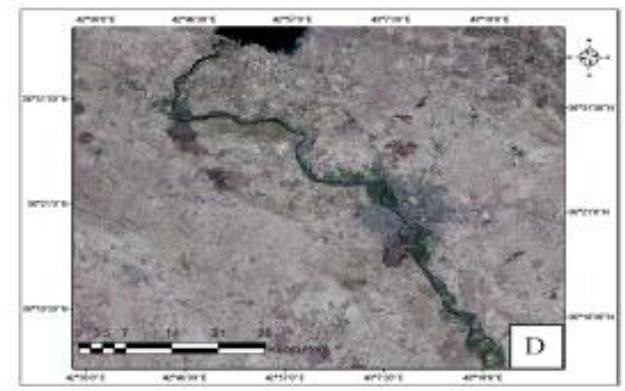

D: $\mathrm{NCC} 1232007$

الشكل 4: مرئيات فضائية محسنة متعاقبة زمنيا لمحافظة نينوى

ثالثا: التحليل الطيفي للنماذج

تم استخدام جهاز التحليل الطيفي (ASD) لإعداد منحنيات الانعكاسية الطيفية للأجسام المختلفة (Spectral reflectance curve) (2500-350) نانومتر، اذ يتم الحصول على قياسات الانعكاسية الطيفية على ثلاث مراحل: يوجه الجهاز في المرطة الأولى الى لوحة المعايرة (Calibration panel) ذات انعكاسية مستقرة معروفة ويستخم هنا التشعيع (Irradiance) الوارد الى موقع القياس. بينما يوجه الجهاز في المرطة الثانية فوق الهدف

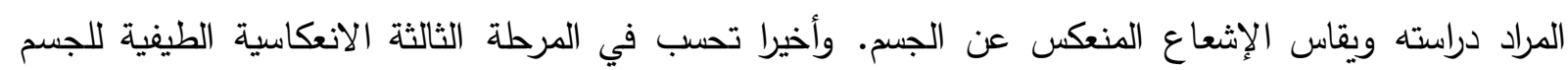
على شكل نسبة بين قياس الطاقة المنعكسة في كل من مجالات الملاحظة الطيفية وبين الشعاع الكلي المقاس في كل طيف. يمثل الثكل (5) صورة الجهاز المستخم.

$$
\text { فحص نماذج التزب 5: يوضح طريقة }
$$

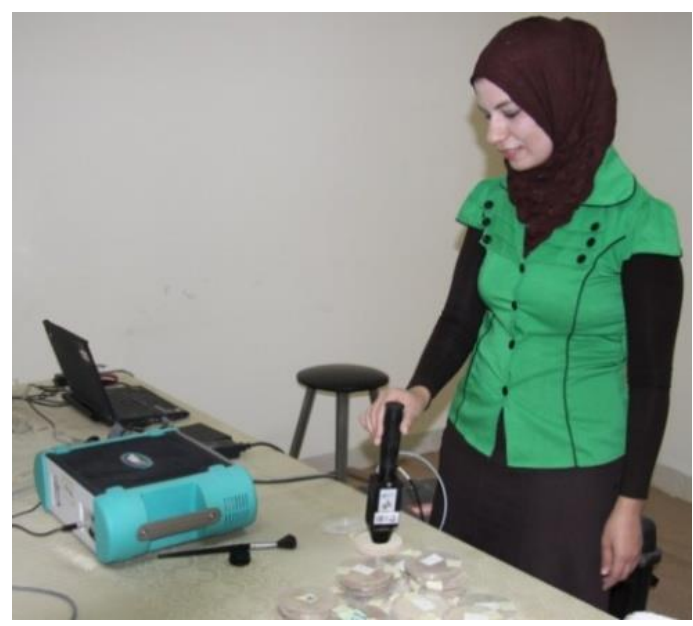


وفيما يأتي نتائج التحليل الطيفي لنماذج التربة المأخوذة من المواقع التي ظهرت بشكل شذوذ طيفي في المرئية الفضائية الملتطة عام 2001 (الجدول 2). تم فحص النماذج بصورة مبدئية بواسطة جهاز عداد كايكر والذي يتم استخدامه من قبل الفرق التابعة لوزارة البيئة عند الذهاب الى المواقع المعائة المدمرة. اولاً: موقع مخازن علان يمكن ملاحظة التغير في قيمة الانعكاسية للنماذج التي اعطت انعكاسية واطئة للنماذج المأخوذة من داخل

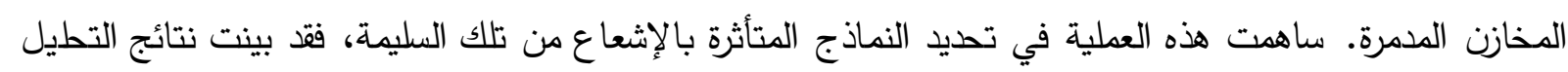

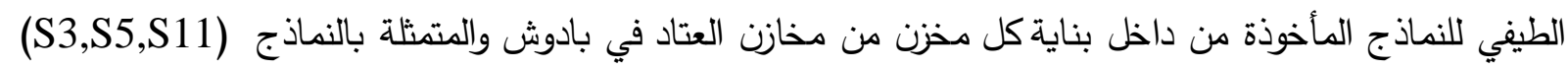

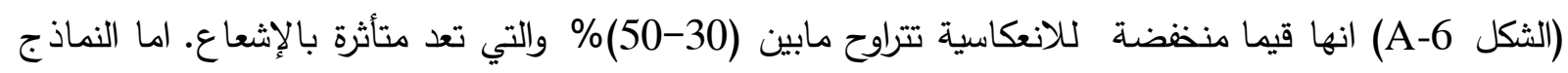
(الثكل C-619,S7)

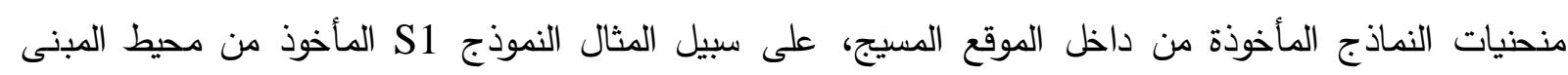

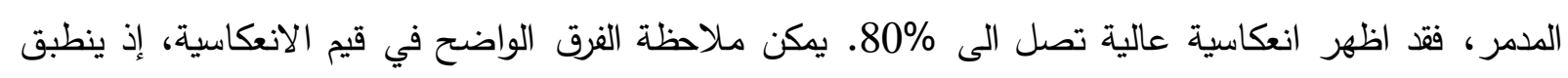

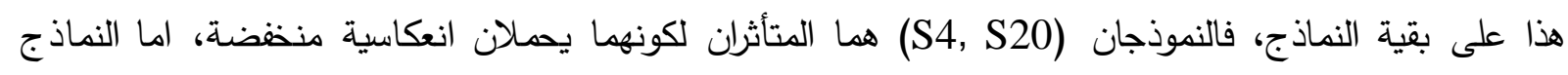

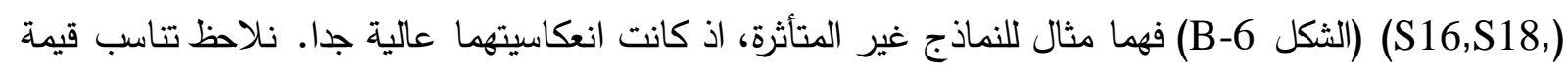

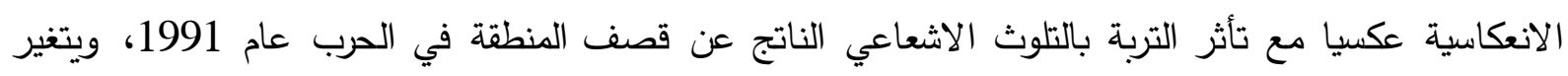

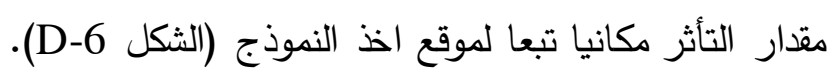

\section{ثانياً: موقع منطقة اسكي موصل}

تمثل النماذج المأخوذة من منطقة اسكي موصل نماذج غير متضررة بالقصف، وبالتالي فهي خالية

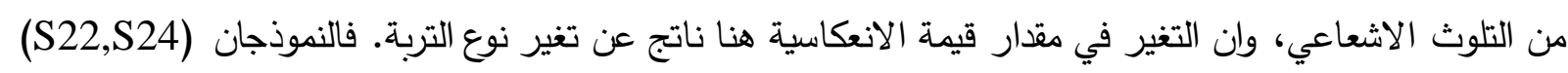

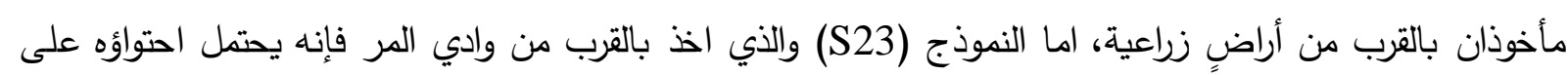

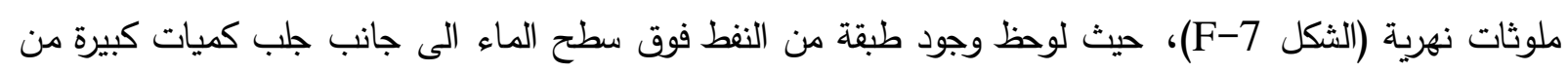
الملوثات اثناء موسم الفيضان والتي غطت سطح السهل الفيضي لهذه المنطقة.

ثالثاً: منطقة سادة وبعويزة

للمقارنة بين نتائج المنحنيات تمت زيارة الجهة الثرقية لدينة الموصل ابتداءً من منطقة سادة وبعويزة وصولا

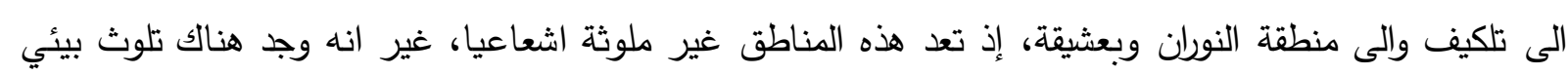

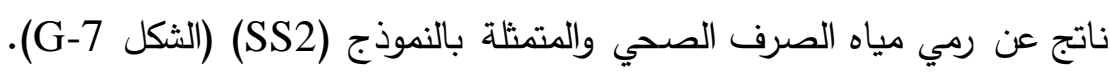


الجدول 2: يبين مواقع أخذ النماذج

\begin{tabular}{|c|c|c|c|}
\hline رقم الشكل & رقم النموذج & موقع النموذج & ت \\
\hline $6-A$ & $\begin{array}{c}\text { S1,S3,S5,S6,S11, } \\
\text { S14,S15 }\end{array}$ & النماذج المأخوذة من ارضية المخازن المدمرة & 1 \\
\hline $6-\mathrm{B}$ & $\mathrm{S} 2, \mathrm{~S} 4, \mathrm{~S} 16, \mathrm{~S} 18$ & النماذج المأخوذة من اسفل المناطق المحيطة بالمخزن & 2 \\
\hline $6-\mathrm{C}$ & S7,S19 & النماذج المأخوذة من الجوانب العليا للمخازن & 3 \\
\hline $6-\mathrm{D}$ & $\mathrm{S} 1, \mathrm{~S} 8, \mathrm{~S} 12, \mathrm{~S} 17$ & النماذج المأخوذة من محيط المخازن & 4 \\
\hline 7-E & $\mathrm{S} 20, \mathrm{~S} 21$ & النماذج المأخوذة خارج موقع المخازن/ زراعية & 5 \\
\hline 7-F & $\mathrm{S} 22, \mathrm{~S} 23, \mathrm{~S} 24$ & النماذج المأخوذة من منطقة اسكي موصل/ زراعية & 6 \\
\hline $7-G$ & L8S1 & النموذج المأخوذ من طريق سادة (غير متاثر)/ زراعية & 7 \\
\hline $7-\mathrm{G}$ & SS2 & النموذج المأخوذ من طريق سادة(متأثر بالتلوث البيئي) & 8 \\
\hline $7-G$ & SS3 & النموذج المأخوذ من منطقة النوران، غير متاثر/ زراعية & 9 \\
\hline
\end{tabular}

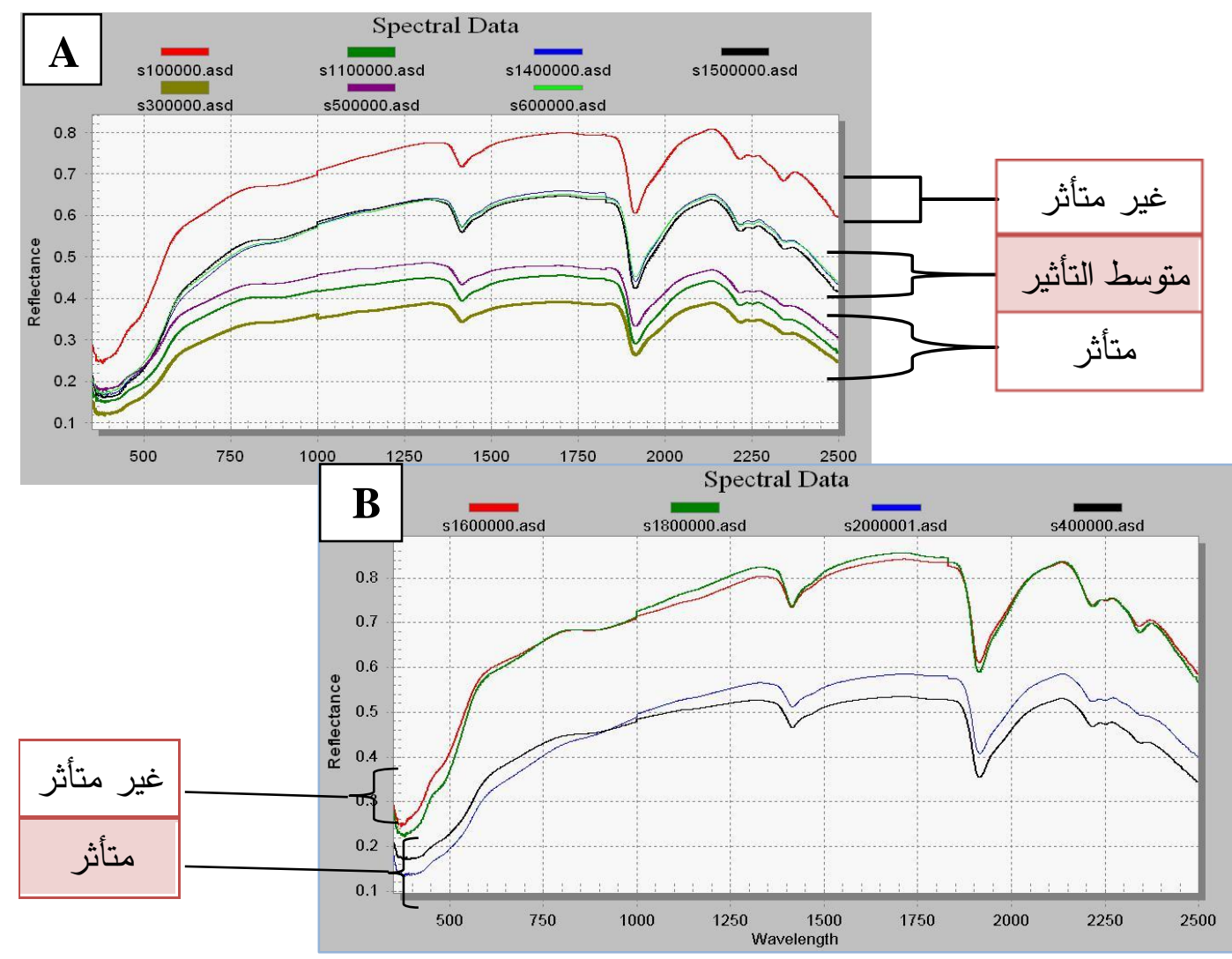

الثكل 6: بوضـح نتائج التحليل الطيفي لنماذج التزب المأخوذة من مخزن العتاد في جبل علان. 

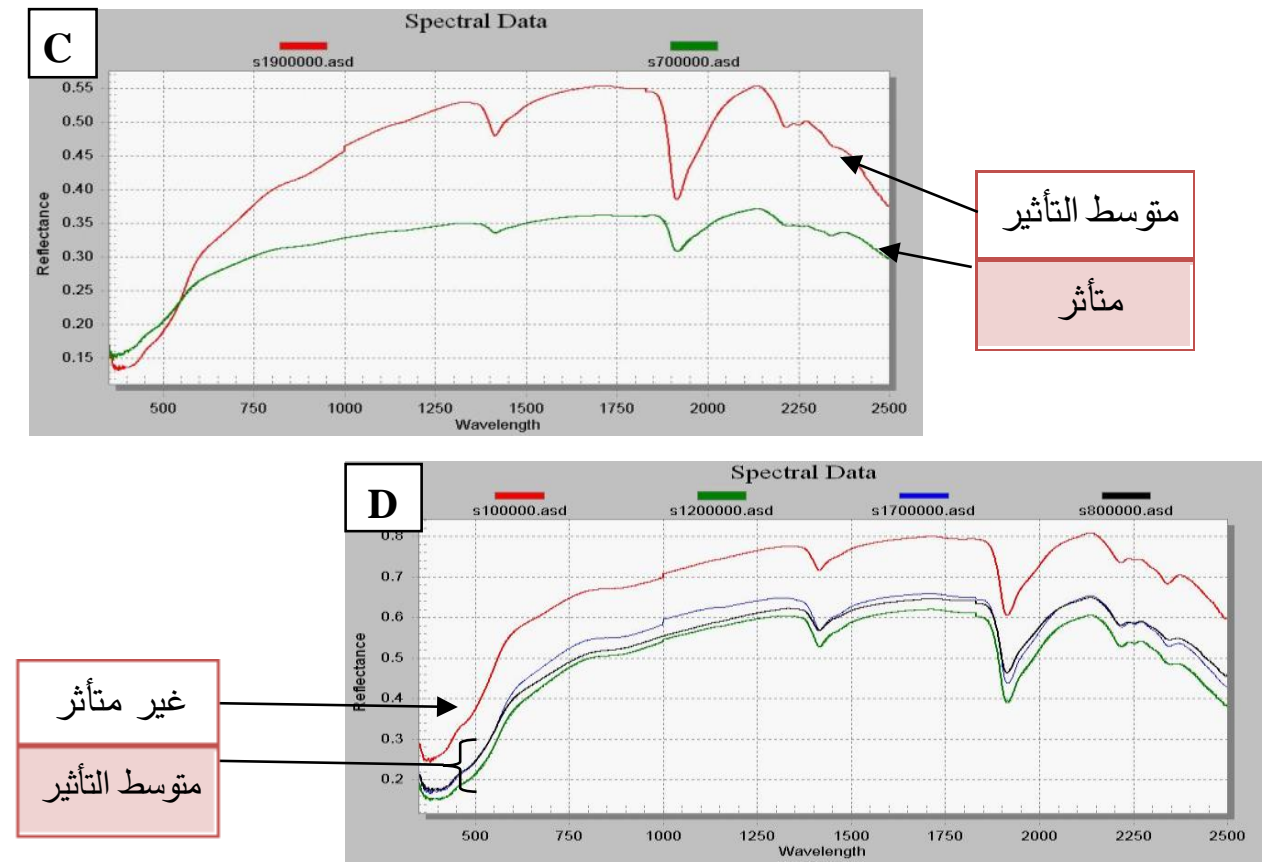

تابع للشكل (6)

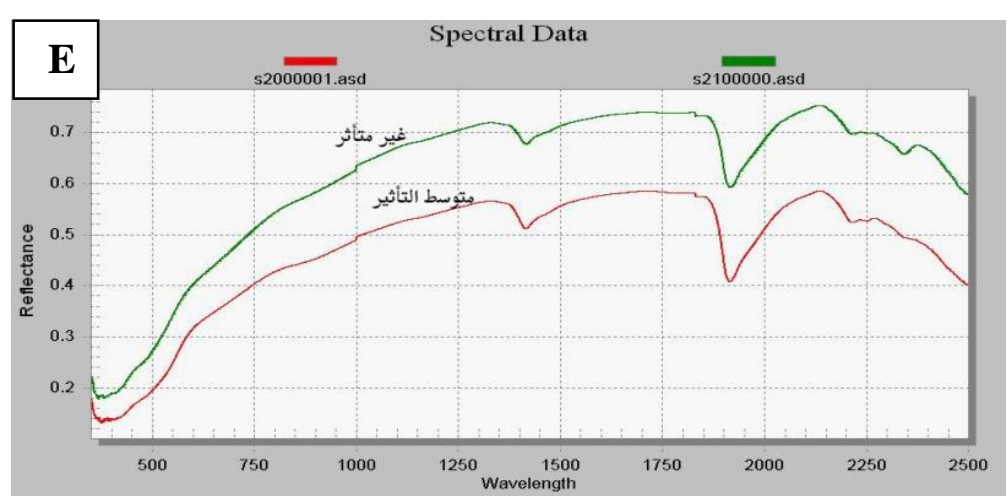

الثكل 7: يوضح نتائج التحليل الطيفي لنماذج
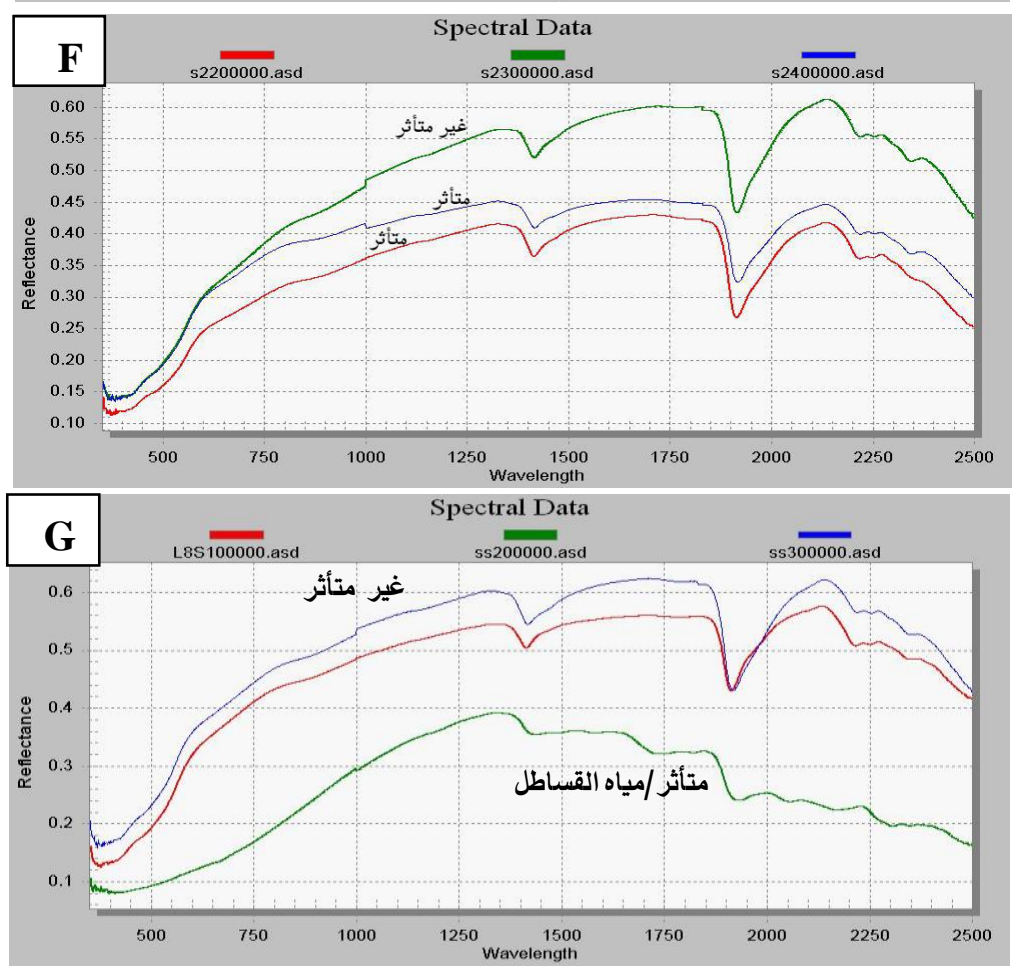


\section{الخارطة الجيوبيئية المعدة لمنطقة الدراسة}

تم تصنيف منطقة الدراسة إلى عدة وحدات بالاعتماد على مجموعة عوامل متعلقة بالبيئة، المكاشف الصخرية وتضاريسها الجيومورفولوجية، نوع الغطاء النباتي وكذلك طبيعة استخدامات الأرض حيث ظهرت هذه الأصناف بانعكاسية تختلف عن بعضها البعض على المرئيات الفضائية (الثكل 8). إلى جانب ذلك يجب على الهفر أن يكون على دراية بجيومورفولوجية المنطقة ونوعية استخدامات الأرض فيها مما يساعد هذا في التعرف على هذه الأصناف ومقارنة جميع هذه الوحدات مع التغيرات البيئية الحاصلة في المنطقة الدراسة.

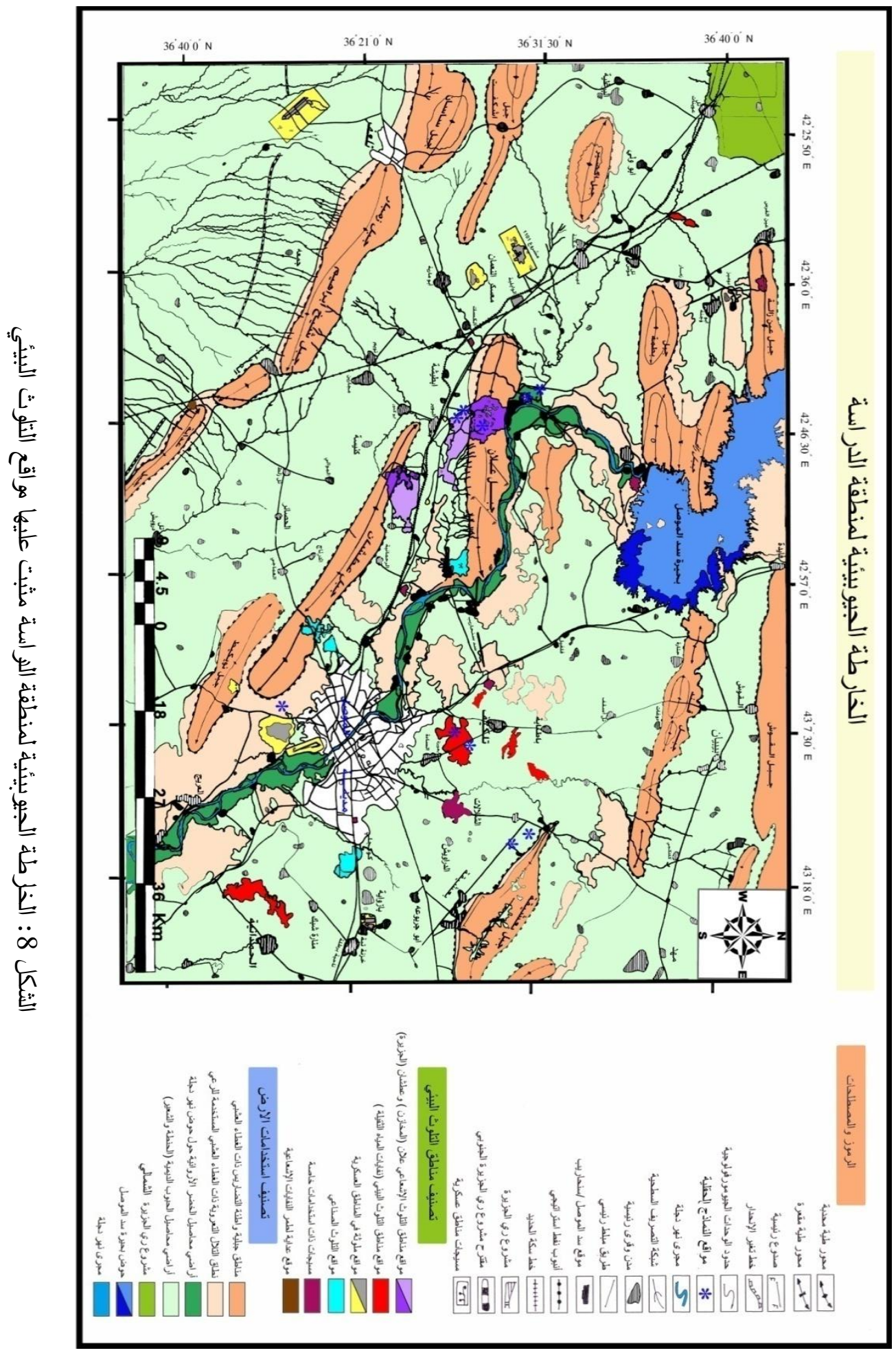




\section{فيزيوغرافية منطقة الاراسة}

تتكون منطقة الدراسة من سلسلة من التراكيب الجيولوجية المدبة (Anticlinal structural zone) المحيطة بمدينة الموصل، إذ تمتد من تركيب بعشيقة في الثمال الشرقي والى تركيب قند في الثمال وصولا لبحيرة سد الموصل ومجرى نهر دجة حيث تفصل البحيرة والنهر مابين المناطق الجبلية الثرقية والطيات الواقعة بالقرب من البحيرة غربا. ثم تبدأ الأرض بالانبساط وتغطيها التربة الخصبة التي تستغل للزراعة الديمية والاروائية مثل

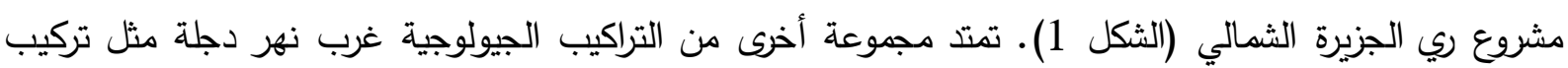
بطمة وعلان وعطشان وشيخ ابراهيم (Al-Daghastani, 2008). ساهمت سلسلة التراكيب الجيولوجية هذه في تكوين منابع أحواض التصريف السطحية ومنها وادي بادوش من خلال شبكة أنماط التصريف التي تثكلت على سفوحها (تركيب علان، عطشان، شيخ إبراهيم). ومن ثم جريانها ضمن محور الطية المقعرة المحصورة بين هذه التراكيب الثلاثة لحين وصولها إلى نهر دجلة قرب قصبة بادوش. تساعد طبيعة الانحدار ووجود أنماط التصريف وطبيعة التربة الهشة على نقل المواد الملوثة الموجودة فيها (مخازن

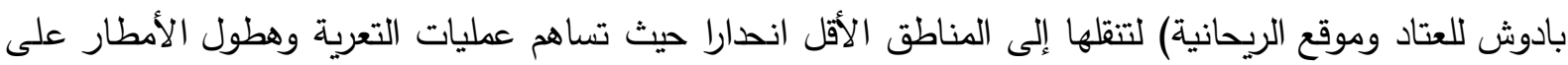

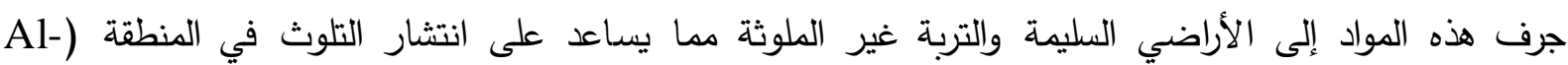

.(Daghastani, 2013

Accumulation/Erosion ) يحيط بهذه التراكيب المحدبة نطاق من السهول التجميعية والتعروية plains ). إذ تم فصل هذه الوحدة بالاعتماد على التغير المفاجئ والسريع في درجة الانحار للتراكيب الجيولوجية المصبة (Break of slope) إلى جانب اختلاف درجة الدكانة والنمط وكذلك اختلاف التعرية التفاضلية بين التكاوين الجيولوجية. تمتاز هذه الوحة باحتوائها على أراضٍ خصبة صالحة للزراعة تتميز بأشكالها المنتظمة حيث تتكون تربة هذه المنطقة من ترسبات حديثة ناتجة عن عمليات التعرية والترسيب لمكاشف الصخور المنتشرة في مناطق المرتفعات التركيبية وذلك بواسطة عدة عوامل منها التعرية التفاضلية والجريان السطحي. بالاعتماد على نتائج التقسير البصري والرقمي ونتائج التوقيع الطيفي لنماذج الترب في مناطق متفرقة في محافظة نينوى تم التوصل الى تصنيف مناطق الثذوذ الطيفي واستخدامات الأرض في خريطة غرضية بمقياس 50000/1 أعدت لهذا الغرض.

\section{تصنيف مناطق التلوث البيئي \\ تم تصنيف مناطق التلوث في منطقة الدراسة حسب نوع التلوث الى:} 1. مواقع مناطق التلوث الإشعاعي: تمت زيارة مواقع مخزن العتاد في تركيب علان بتاريخ (2013/3/9) وهي مقر لأحد الافواج العسكرية التابعة للجيش العراقي حالياً، والتي تم استهدافها من قبل القوات الامريكية في اثناء الحرب على العراق عام 1991 (الثكل 9)، إذ يعتقد بأنها قد قصفت بأسلحة تحتوي على مواد محرمة دوليا كاليورانيوم المنضب (Depleted Uranium) (Al-Azzawi, 2006). تثير الفحوصات المختبرية لنماذج الترب ومنحنيات التحليل الطيفي الى زيادة في نسبة الانعكاسية للنماذج المأخوذة في داخل المواقع المدمرة ضمن Jensen, 1986; Lillesand and ) المدى الطيفي للقناة السابعة والتي تستخدم في الكشف عن المعادن 

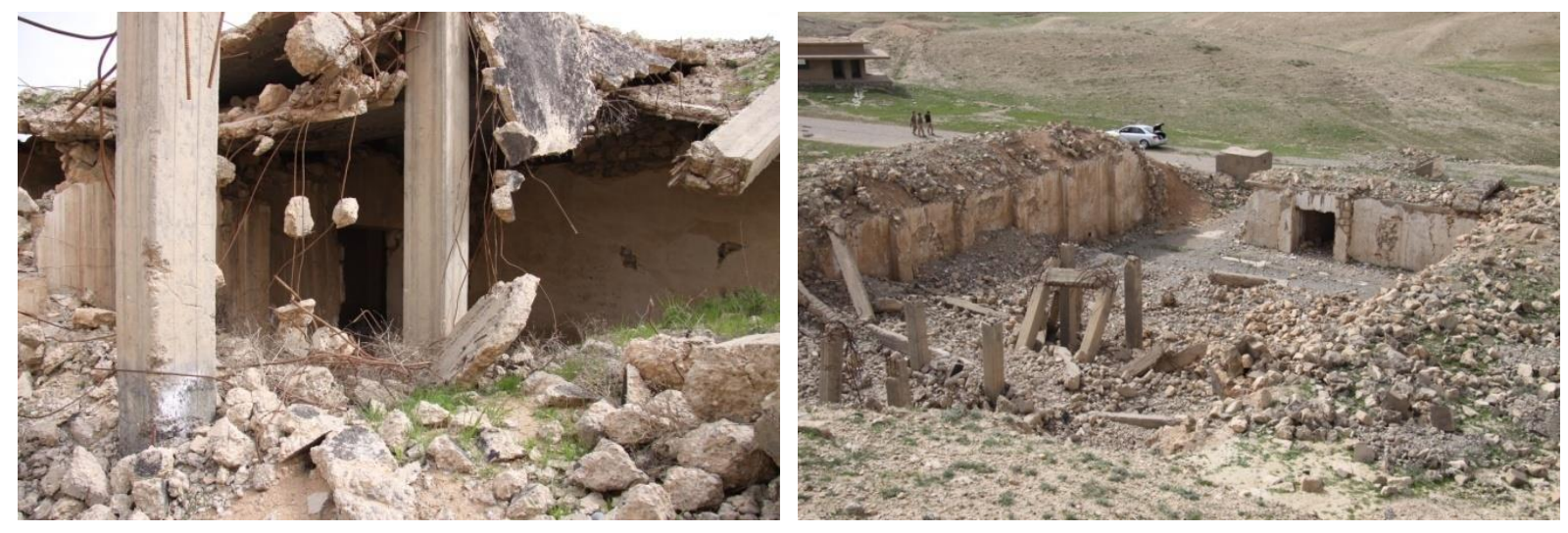

الثكل 9: يوضح أحد المخزن المدموة في تركيب علان.

لم نتمكن من زيارة موقع الريحانية لأسباب امنية. تم تدمير مصنع الريحانية الواقع ضمن جبل عطشان في عام 1991 ايضاً والذي يبعد 30 km غربي مدينة الموصل والذي يعد أحد أهم المواقع المصممة لاستلام مادة اليورانيوم والتي تعرف بال (Yellowcake) وانتاج اوكسيد اليورانيوم UO2 وتتراكلورايد اليورانيوم UC14. وكان

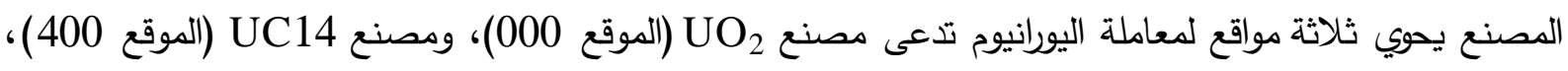
http://www. iraqwatch.org/un/IAEA/iaea-18.htm, ) وثناثة احواض كونكريتية كبيرة لخزن النفايات . accessed at: 2nd/July/2011. ونتيجة لقصف المصنع وعدم السيطرة على المواد الملوثة ظهر الموقع .

بانعكاسية مشابهة تماماً لموقع مخازن بادوش (الثكل 2) (الداغستاني واخرون، 2004). صدر تقرير عن مركز الوقاية من الاشعاع التابع لوزارة البيئة بتاريخ (2004/7/3) يظهر المستويات المرتقعة للإشعاع في موقع الجزيرة مبينة بالجدول (3). تم قياس نسب الاشعاع لهذا الموقع المدمر من قبل قوات الاحتلال.

الجدول 3: قياسات فرق وزارة العلوم والتكنولوجيا/دائرة المواد الخطرة وبحوث البيئة.

\begin{tabular}{|c|c|c|c|}
\hline المـلاحظات & $\begin{array}{c}\text { قياسات جهاز } \\
\text { Seintrex c/sec }\end{array}$ & $\begin{array}{c}\text { قياسات جهاز } \\
\text { Wallac mr/h }\end{array}$ & لحداثيات الموقع \\
\hline منطقة دخول وخروج/البيوابة الجزية الريخية & $75-50$ & اقل من0.05 & $\begin{array}{l}X=05090 \\
Y=29350\end{array}$ \\
\hline 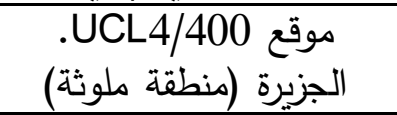 & $3000-2000$ & $1-6$ & $\begin{array}{l}X=05088 \\
Y=29401\end{array}$ \\
\hline خف الجدار الكونكريتي & $250-100$ & $0.3-0.1$ & ا الكونكريتية \\
\hline
\end{tabular}

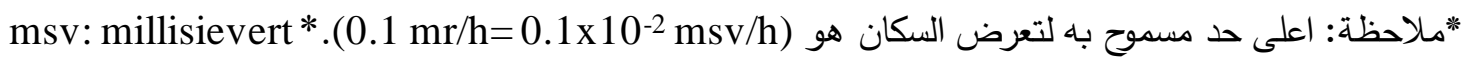
mr: milliradian

2-مواقع مناطق التلوث البيئي (نفايات المياه الثقيلة): تحتوي مياه الصرف الصحي على العناصر الثثيلة والتي يمكن ان تدخل الى جسم الإنسان ضمن الدورة الطبيعية المعروفة (تربة- نبات- حيوان- إنسان- تربة). أن تركيزها العالي في التربة يسهل امتصاص اجزاء منها من قبل النبات (الحنطة والثعير مثلاً)، وبالتالي احتمال انتقالها الى الحيوان أو الإنسان. وسهلت عمليات تحليل الانسجة الحية المختلفة الى الاستتتاج أنه كلما زادت 


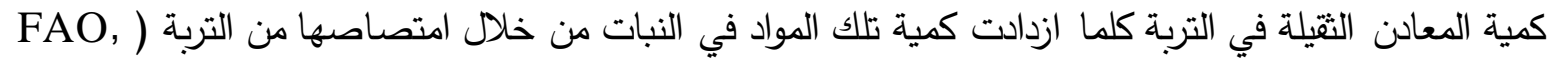
1995). ان السمة المميزة للمعادن الثقيلة هي قدرتها على تحطيم حلقات الدورة الطبيعية عندما تدخل اليها،

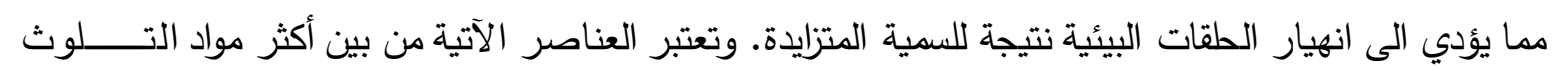
والتســم وهي حسب تركيبها الكيمياوي Cl, F, Al, Cr, Se, Ni, Cd, Hg, Pb, Sr, As (حنوش،

عند زيارة بعض المواقع حقليا في منطقة سادة وبعويزة قرب تلكيف بتاريخ (2013/3/14) وفحص النماذج المأخوذة منها تبين احتواؤها على ملوثات ناتجة عن طرح المياه الثقيلة (مياه الصرف الصحي الثقيلة) بأسلوب عشوائي يعكس فقدان الرقابة البيئية من قبل مديرية بيئة نينوى بسبب الوضع الامني الراهن في المحافظة. وبسبب كون هذه المناطق غير مهيأة ولا مخصصة رسميا كمواقع للطمر الصحي لهذه المخفات بل يتم رميها على السطح وبالقرب من أراضٍ تستخم لزراعة الحنطة والثعير او الرعي (الشكل 10). وعندما يقوم الفلاحون بحرث هذه الأراضي في موسم التحضير للزراعة تؤدي عمليات الحرث إلى قلب التربة فتتناخل المخلفات مع التربة ولذلك لا نجد هذا الثذوذ في المرئيات المأخوذة في فترات زمنية لا تتناسب مع وقت رميها، علما بأن المرئية الملتقطة عام 2001 (الشكل 1) أعطت شذوذا مشابها لمواقع التلوث الإشعاعي، الأمر الذي جعلنا نبحث عن اسباب مواقع هذا الثذوذ الطيفي في المرئيات والذي تبين جليا بأنها مواقع سكب نفايات المياه الثقيلة

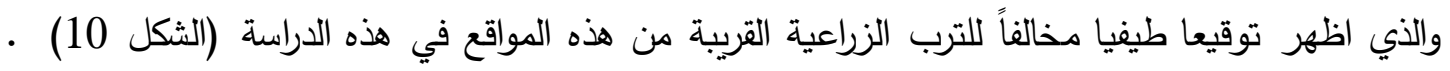

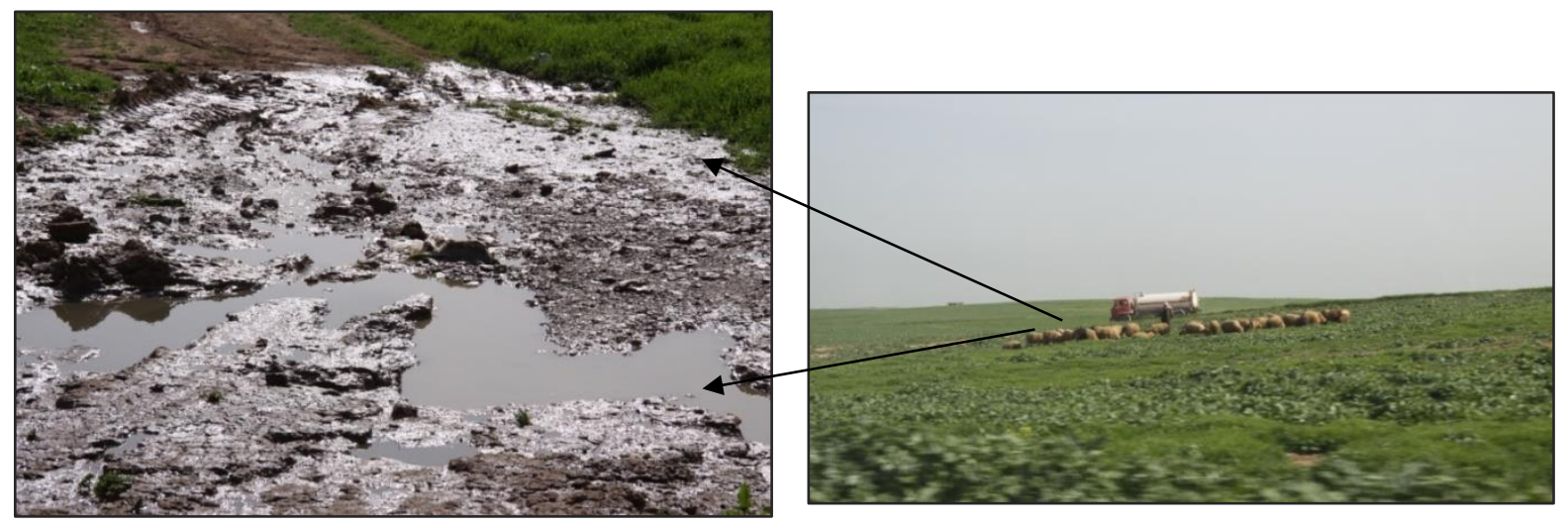

الثكل 10: يوضح سكب مياه النفايات الثقيلة فوق الأزاضي الزراعية قوب تلكيف

3- مواقع ملوثة في المناطق العسكرية: تميزت مواقع هذا الصنف بثذوذ طيفي والناتج عن قصف هذه المواقع

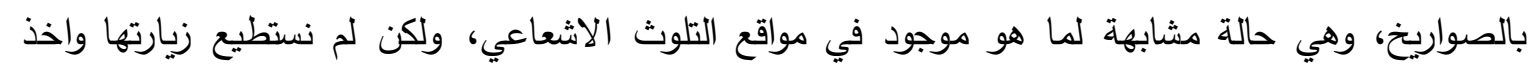
النماذج منها لأسباب امنية. تشمل مواقع هذا الصنف كلا من مطار الموصل وتلعفر ومشروع 1101 العسكري وكذلك معسكر النعمان. تميزت هذه المواقع بانعكاسية منماثلة تقريبا وشاذة بنفس الوقت عن المناطق التي ظهرت على المرئية الفضائية، اذ ساعد في تحديدها أشكالها المنتظمة كونها مواقع عسكرية محمية ومسيجة تختلف عما يحيطها (الثكل 11). ونلاحظ أيضا أنه في داخل كل موقع من هذه المواقع لون مميز يختلف هوناه عن خارجه وهذا الاختلاف ناتج عن طبيعة استعمالات الموقع والوحدات البنائية له الى جانب مواقع مميزة تمثل مواقع القصف بالصواريخ داخل هذه المسيجات أثناء الحرب عام 1991 والحروب اللاحقة. ويذكر هنا 
فائدة تقنية التحس النائي في مراقبة هذه المواقع العسكرية والمطارات عن بُعد وإمكانية تحديد مواقعها ونشاطاتها وهو ما تقوم به الدول المتقدمة وكذلك مفهوم التجس على نشاطات هذه المواقع والتي قامت بتحديد موقع هذه المناطق جغرافيا وقصفها في الحروب التي خاضتها ضد العراق.

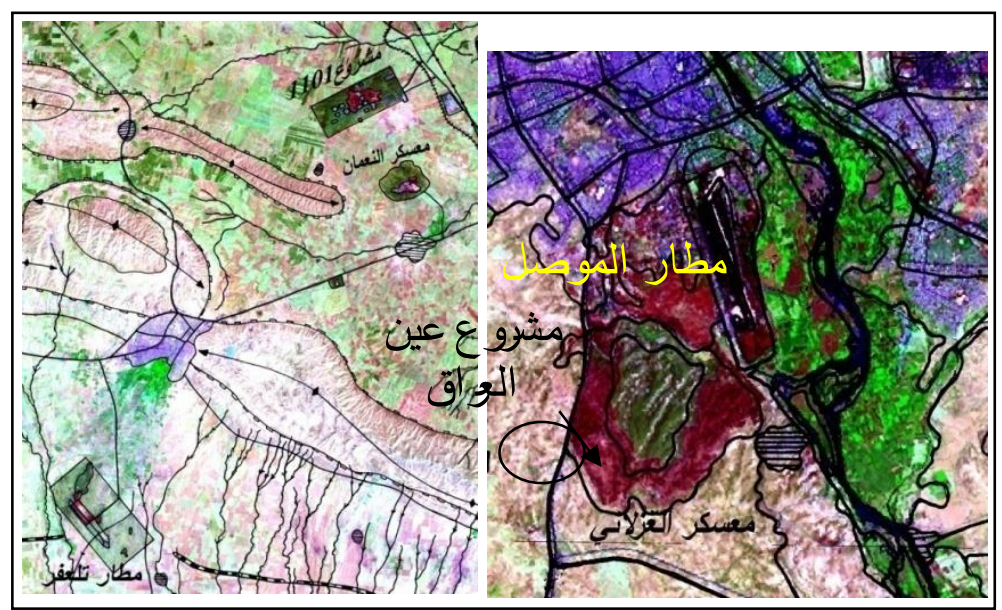

الثكل 11: نماذج مقتطعة تبين المواقع الملوثة في المناطق العسكرية

إن المنشآت الحكومية (مشروع 1101) مثلا التي تقع في غرب منطقة الدراسة قرب منطقة الكسك على طريق موصل- ربيعة وهي منشآت عسكرية تم بناؤها في اواخر الثمانينات من قبل الثركات اليوغسلافية، وتميزت بأشكالها الهندسية وسعة مساحتها ونمطها الذي ظهرت بهه، إضافة إلى اللون الأزرق الفاتح الذي ظهر في المرئية نتيجة لانعكاسات الأبنية الكونكريتية فيها عن المناطق غير المستخدمة للبناء. تظهر المرئيات ان قسما من هذه الابنية قد تم قصفها وظهرت بنفس لون الثذوذ الطيفي للمناطق العسكرية الاخرى. 4-موقع عداية لطمر النفايات: ان النفايات الصلبة والملوثة الناتجة عن مصنع الريحانية المدمر تم نقلها ودفنت في موقع قريب من قرية عداية التي تبعد حوالي 23 km عن موقع الريحانية من قبل الجهات الحكومية آنذاك،

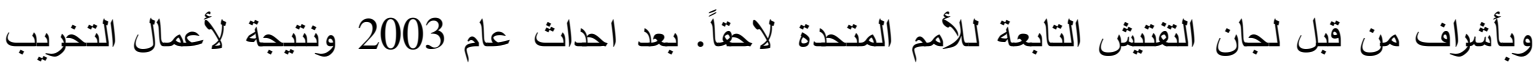
والعبث والسرقة للمواد الملوثة باليورانيوم وسرقة بعض الاجهزة والمعدات المطمورة الى مناطق غير معلومة من قبل بعض الجهلاء مما أدى الى انتشار ظاهرة التلوث الاشعاعي بالمنطقة (Ali, 2011). وبسبب الطوق لإق الامني الكبير على المنطقة كان من الصعب جدا الذهاب الى القرية بغية الحصول على النماذج والعينات لغرض اجراء الفحوصات المختبرية عليها بسبب عدم حصولنا على الموافقات الامنية لدخول الموقع. بالرغم من صغر مساحة المنطقة (موقع طمر عداية)، إلا انها ظهرت على المرئية الفضائية لعام (2007) من خلال الوحدات الصورية المعبرة عنها بانعكاسية مميزة تدل على وجود شذوذ طيفي ناتج عن تأثير التلوث الاشعاعي في المنطقة. ولكون هذا الموقع قد أُنشئ بعد عمليات القصف على موقع الريحانية ليكون موقعا مخصصا لطمر النفايات الخطرة، نرى أن هذا الثذوذ لم يظهر اطلاقا في المرئيات الفضائية قبل احداث 


\section{الاستنتاجات والتوصيات}

ساهمت عمليات التقسير البصري والرقمي والتحليل الطيفي لمعطيات التحس النائي في إعداد الخارطة الجيوبيئية الخاصة بمنطقة الدراسة والتي ساعدت في معرفة وتحيد مناطق التلوث وتصنيفها، إذ أصبحت هذه الخارطة مرجعا حديثا وهاما للحالة البيئية في محافظة نينوى ولمتخذي القرار في وزارة البيئة. أعطت منحنيات التوقيع الطيفي للنماذج الحقلية فكرة عن المواقع التي تزداد فيها نسبة وجود اليورانيوم

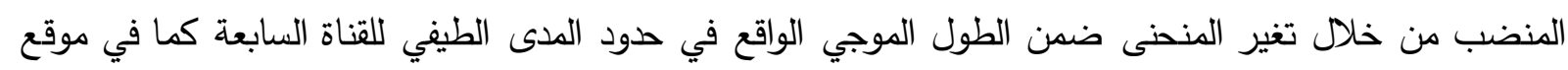
بادوش، بينما اختلف التوقيع الطيفي للنماذج الحقلية المأخوذة من موقع رمي نفايات المياه الثقيلة والتي كانت منتشرة في عموم سهل نينوى. اثبت التطيل الطيفي أيضا بان المناطق غير الملوثة مثل النماذج المأخوذة من مواقع النوران وبعشيقة ونموذج أسكي موصل قد أعطى منحنيات اعتيادية مطابقة للمنحنيات القياسية للتربة. أصبح من الضروري متابعة التغير الحاصل في درجة الدكانة (الثذوذ الطيفي) الموجود في التعاقب الزمني للمرئيات الفضائية ومحاولة السيطرة على مصادر التلوث ضمن الإمكانيات المتاحة. فيمكن السيطرة على التلوث البيئي على سبيل المثال من خلال تهيئة وتوفير أماكن خاصة لرمي المياه الثقيلة وتجنب رميها فوق الأراضي الإني الزراعية، ومحاسبة المقصرين في ذلك. أما فيما يخص التلوث الإشعاعي، فأثثتت الدراسات التي قُدمت في ورشة العمل المتخصصة في مجال طمر النفايات مدى خطورتها وتأثيراتها على الصحة والبيئة للفترة من (15-17)/ لردئه 2011/11 في جامعة لوليو التكنولوجية (السويد)

http:/www.Itu.se/research/subjects/Geotechnicalnicalengineering/Konferenser/Landfill workshop-2011/Final-Schedule.

وأن أهم طرائق المعالجة هي باستخدام طريقة الطمر (Landfill) باستخدام الطين والذي يتوفر بنقاوة عالية في العراق وضمن المواصفات العالمية المتبعة في مثل هذه الكوارث البيئية.

\section{المصادر العربية}

الداغتاني، حكمت صبحي، 2004. مبادئ التحس النائي وتقسير المرئيات. دار ابن الاثير للطباعة والنشر ، جامعة الموصل، 562 صفحة.

الداغتاني، حكمت صبحي، البناء، ريان غازي، والديوه جي، بسام محد، 2004. دراسة ظاهرة الثذوذ الطيفي في تركيبي علان وعطشان شمال غرب العراق باستخدام معطيات التحس النائي. المجلة العراقية لعلوم

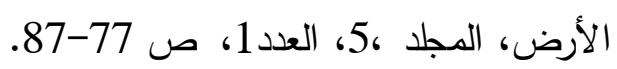

حنوش، علي حنوش, 2000. العراق: ومشكلات الحاضر وخيارات المستقبل، دراسة تحليلية عن مستويات تلوث البيئة الطبيعية والبيئة الاجتماعية. الطبعة الأولى، دار الكنوز الأدبية، بيروت-لبنان, 251 صفحة.

\section{المصاير الأجنبية}

Al- Azzawi, Souad N., 2006. Depleted Uranium Radioactive Contamination in Iraq. An Overview, Mamoun University for Science and Technology, http:/www. brussellstribunal.org/pdf/DU.Azzawi.pdf. 
Al-Daghastani, H. S., 2013. Using Reflection Anomalies to Detect Radioactive Contaminations in Nineveh Governorate Northern Iraq, International Journal of Enhanced Research In Science Technology and Engineering, Vol. 2 ISSUE 2, pp.1-7.

Al-Daghastani, H. S., 2008. Land Use and Land Cover of Nineveh Governorate Using Remote Sensing Data, Iraq Journal of Erath Sciences, Vol. 8, No: 2 pp.17-26.

Ali, S. H., 2012, Utilities of GIS and Remote Sensing Data in the Spatial Analysis of the Radioactive Contamination Site in Nineveh Province, International Journal of Enhanced Research In Science Technology and Engineering, Vol. 1 ISSUE 3, pp.1-11.

Curran, P. J., 1985. Principles of Remote Sensing, Longman, London.

Faust, Nickolas 1., 1989. Image Enhancement, Vol. 20, Supplement 5 of Encyclopedia of Computer Science and Technology edited by Allen Kent and James G. Williams, New York, Marcel Dekker, Inc.

FAO 1995. Food and Agriculture Year Book, Rome, Vol. 49.

http://www. iraqwatch.org/un/IAEA/iaea-18.htm, accessed at: 2nd/July/2011.

http:/www.Itu.se/research/subjects/Geotechnicalnicalengineering/Konferenser/Land fill workshop-2011/Final-Schedule.

Jensen, J. R., 1986. Introductory Digital Image Processing. A Remote Perspective, Prentice - Hall, Englewood Cliffs, N.J.

Lillesand, T., Kiefer, R., and Chipman, J., 2004. Remote Sensing and Image Interpretation, $5^{\text {th }}$ d.New York, John Wiley and Sons.

Sabins, F. F., JR, 1987. Remote Sensing Introduction, W. H. Freeman and Principles and Company Sanfrancisco.

Verstappen, H. Th. and Van Zuidam, R. A., 1975. Use of Aerial Photographs in Geomorphology. International Institute for Aerial Survey and Earth Sciences (ITC), Enschede, Netherlands. 